\title{
Posture Determination for Bridge Girder and Distributed Incremental Launching Devices
}

\author{
Hong Zhang ${ }^{1}$, Xiaoping Zhang, ${ }^{2, *}$ Yuxue Chen ${ }^{3}$, Daoping $\mathrm{Xie}^{2}$ and Qiang Guo ${ }^{2}$ \\ ${ }^{1}$ CCCC Second Harbor Engineering Company Ltd., 430040, China \\ ${ }^{2}$ CCCC Wuhan Harbor Engineering Design and Research Company Ltd., 430040, China \\ ${ }^{3}$ Huazhong University of Science and Technology, 430074, China \\ *Corresponding author
}

\begin{abstract}
The posture of the bridge girder plays a very important role for the safety and efficiency of the bridge construction. This paper mainly proposed a mathematical method for determining the position and orientation of bridge girder and distributed Incremental Launching devices. Firstly, the background of incremental launching construction is introduced. In addition, the mechanical and hydraulic design of the launching device and its iterated construction movements are described. By analyzing the characteristics of incremental launching method and the distributed launching devices, the posture of single device and the bridge girder are determined mathematically. Further, the posture determination method is integrated into the bridge launching construction surveillance system. The application of this method is practically verified in the launching construction of Fengxi suspension bridge, finally.
\end{abstract}

Keywords-posture determination; incremental launching method; bridge girder; launching trajectory error

\section{INTRODUCTION}

The incremental launching method is widely used to construct various kinds of bridges in urban, canyon, the regions across rivers and offshore where traffic, geology and topography conditions are limited [1-6]. Due to the excellence on device integration, high bearing capacity and excellent implementation of construction compare to bracket erecting and dragging-type launching method [7-9], the bridge girder with a temporary guiding nose [10-11] is capable of being assembled on one side of the obstacle and launched direct to the other side without previous constructing a large number of temporary supports or using large-scale hoisting devices.

\section{INCREMENTAL LAUNCHING SYSTEM}

\section{A. Incremental Launching Method}

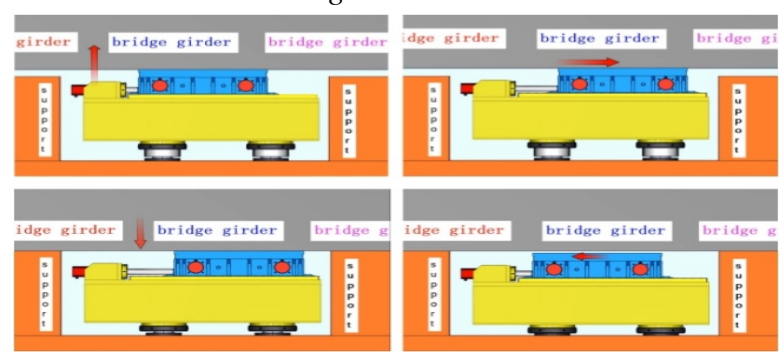

FIGURE I. THE FOUR INCREMENTAL LAUNCHING STEPS OF CONSTRUCTION SEQUENCE
The incremental launching device is the tool for launching construction. Often, the bridge girder is launched by means of using multiple pairs of them on the pies or temporary pies. As shown in Figure II, the construction sequence of incremental launching includes 4 steps, which are lifting up, pushing forward, lowering down and resetting.

When the IL devices are ready to launch the bridge girder, the launching interfaces are simultaneously contact with the bottom surface of the girder with proper preload. Then, the lifting jacks of each IL device are pulling upwards so that the girder is detached from the supporters until the launching height reaches the designed value. After that, the pulling jacks stretch out, along with the girder in terms of the static friction of each contact. When launching distance within every launching sequence is reached, the lifting jacks pull back to its lifting zero position, during which the girder lowers down until detaching with every IL devices and sustained by supporters or temporary pies. Finally, the pulling jacks retracted, and the IL devices pull back to their pushing zero positions and ready for the next iterated launching sequence. To note that, the launching construction of bridge girder needs intermittent transverse adjustment due to construction uncertainties like generation of sliding friction during launching, or curve features of girder itself in horizontal plane.

\section{B. Incremental Laucnhing Device}
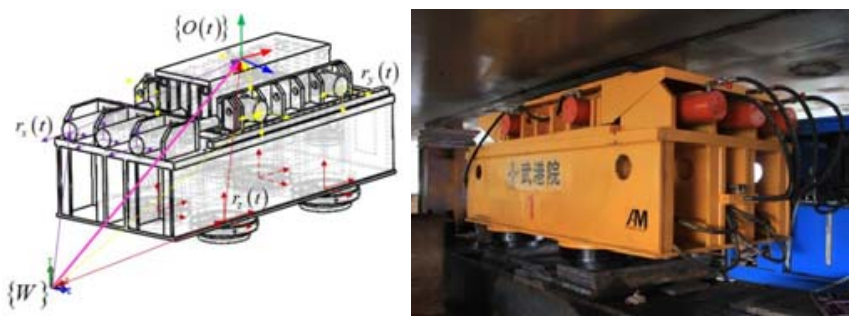

FIGURE II. THE NEW INCREMENTAL LAUNCHING DEVICE

In order to properly satisfy the requirements of the launching movements during each iteration of construction sequence, the launching device itself needs corresponding carrying capacity and flexible movement coordination. Thus, as shown in Figure II, the mechanical structure of IL device is designed as a $2.43 \mathrm{~m} * 1.1 \mathrm{~m} * 1.11 \mathrm{~m}$ bearing case, on which two orthogonal sliding layers are assembled. The bearing structure is supported by 4 lifting jacks of maximum lifting force $4 * 4000 \mathrm{KN}$ with the stroke of $300 \mathrm{~mm}$. The lifting jacks are 
spherically hinged so that IL device is capable of local vertical moving and 3-dimensional angular fine tuning which are in the directions of linear $z$ and angular $x, y, z$. The IL device can easily adapted to the complex curve feature of bottom surface of the girder by controlling the lifting heights of each jacks. The middle sliding layer is connected to 3 paralleled pushing jacks of maximum $3 * 500 \mathrm{KN}$ with the stroke of $350 \mathrm{~mm}$. When pushing the bridge girder in direction $x, 3$ jacks stretch out together. While, only the middle jack works when IL device is resetting. The top sliding layer's independent movement which is generated by 4 single-acting jacks of maximum $2 * 750 \mathrm{KN}$ pushing force with the stroke of $6 \mathrm{~mm}$, is designed in order to adjust the bridge girder's position in transverse $\mathrm{y}$ direction.

There are PTFE material between layers' surfaces to reduce the steel to steel frictional effects for the pushing, resetting and adjusting movement. Meanwhile, there is a cushion layer install on the top of the layer as the contact media to ensure the surface contact is generated between the bridge girder and IL devices.

\section{Hydaulic system of Incremental Launching Device}

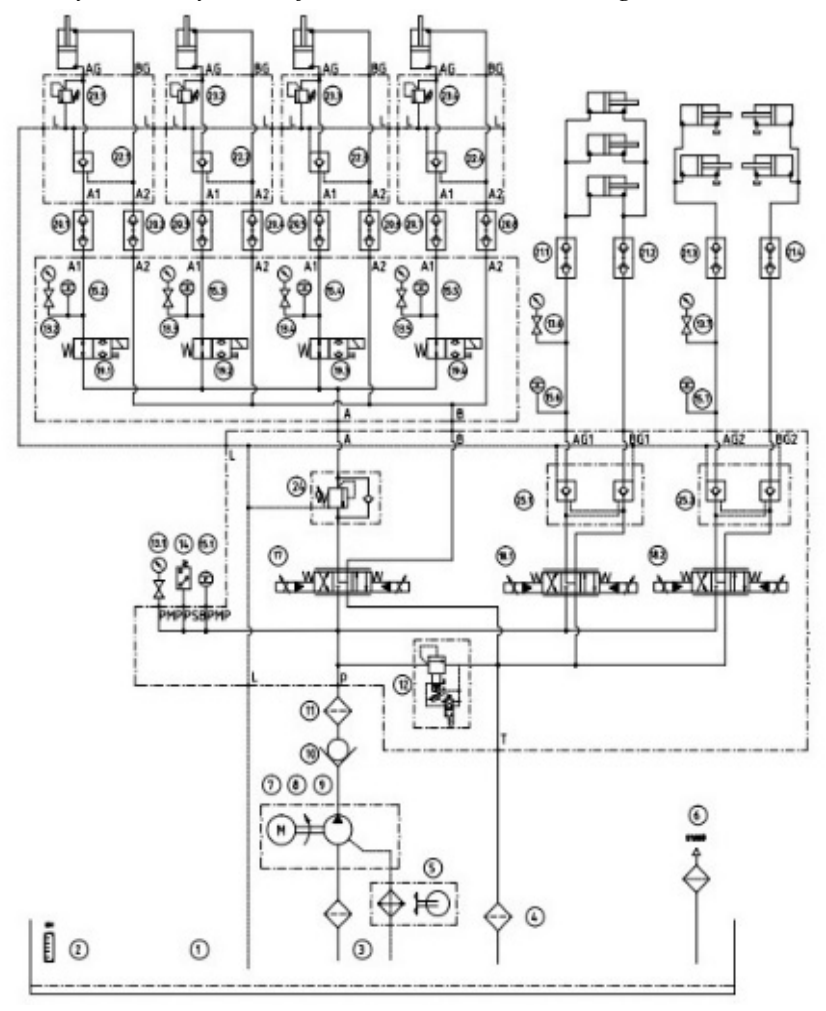

FIGURE III. THE HYDRAULIC DESIGN FOR THE INCREMENTAL LAUNCHING SYSTEM

To fulfill IL device's movements during launching sequence, the specified hydraulic system is designed to provide the power for the IL devices, as shown in Figure III. The system mainly includes a quantitative plunger pumping with $15 \mathrm{KW}$ frequency motor to provide maximum $70 \mathrm{Mpa}$ pressure with the flow rate of $12 \mathrm{~L} / \mathrm{min}$, or to provide $31.5 \mathrm{Mpa}$ pressure with the flow rate of $23 \mathrm{~L} / \mathrm{min}$ for light duty construction condition. 3 proportional direction values are adopted for fine tuning the flow rate of lifting jacks, pushing jacks and adjusting jacks, respectively. In term of using closelooped PID control algorithm and multi-point synchronous launching strategy, the launching movement's synchronization accuracy of all IL devices are guaranteed. Other components such as relief valves, balancing valves, one-way valve, safety valves are modular selected to prevent system pressure overload or pressure loss, and to maintain the system pressure, etc.

Four lifting jacks are paralleled connected to the proportional direction value so that the lifting pressures of all cylinders are well balanced. The 3 pushing jacks and 4 adjusting jacks are configured in the same manner to make sure the reliability and stability of overall launching process.

\section{POSTURE DETEMINATION OF IMCREMENTAL LAUNCHING CONSTRUCTION}

The following chapter mainly proposes a mathematical method of determining the posture of the IL device and corresponding bridge girder, which is launched in terms of multiple IL devices at distributed working stations.

\section{A. Posture Detemination of Single IL Device}

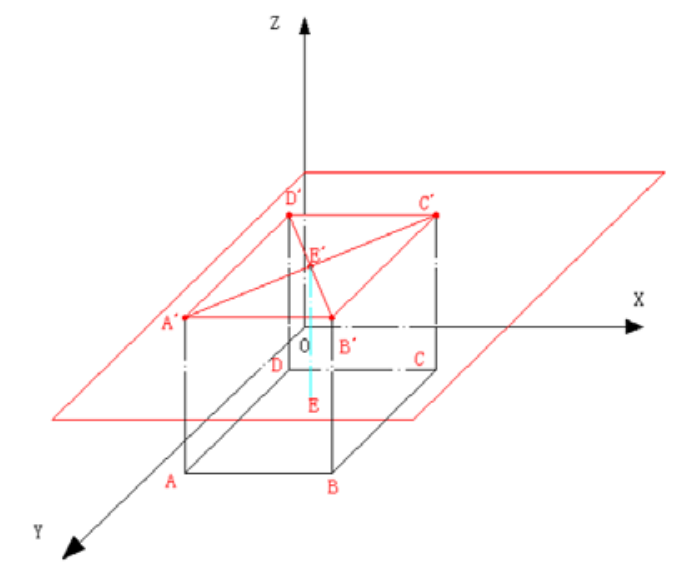

FIGURE IV. THE CONTACT POINT OF SINGLE IL DEVICE

We supposing the coordinates of the contact point $\mathrm{H}^{\prime}$ between the bridge girder and the single IL device is $\left(X_{H}{ }^{\prime}, Y_{H}\right.$, $Z_{H}$ '), which are monitored by the position sensor at lifting, pushing and adjusting direction, respectively. During launching construction, the value of $X_{H}$ ' and $Y_{H}$ ' are the directly decided. Yet, the value of $Z_{H}$ ' is determined by the heights of four lifting jacks. As shown in Figure IV, the bridge girder is lifting by the IL device at the local working station, and the four supporting points of single IL device are supposed to be $A^{\prime}, B^{\prime}, C^{\prime}$ and $D^{\prime}$. Then, the lifting jacks' heights are readable from the corresponding position sensors.

$$
A A^{\prime}=z_{1}, B B^{\prime}=z_{2}, C C^{\prime}=z_{3}, D D^{\prime}=z_{4}
$$

Therefore, the height of intersection point E' of line A'C' and line B'D' is redundant determined as: 


$$
Z_{e}^{\prime}=\frac{Z_{1}+Z_{3}}{2}, Z_{e}^{\prime \prime}=\frac{Z_{2}+Z_{4}}{2}
$$

If $Z_{e}^{\prime}=Z_{e}^{\prime}$, the intersection point $E^{\prime}$ is the contact point $H^{\prime}$ of the launching plane $A{ }^{\prime} B$ ' $C$ ' $D$ ', which between the IL device and the bridge girder. Once $Z_{e}^{\prime} \neq Z_{e}^{\prime}$, there are 4 conditions for determining the position of contact point $\mathrm{H}^{\prime}$.

- $\quad$ Point $A^{\prime}$ is without contact.

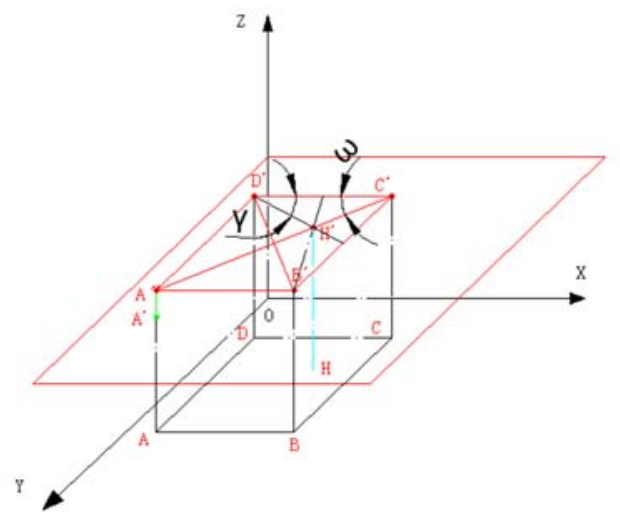

FIGURE V. THE SPATIAL PRESENTATION OF LAUNCHING CONTACT POINT(A)

In this condition, as shown in Figure $\mathrm{V}$, point $A^{\prime}$ is without contact when $z_{1}<z_{2}+z_{4}-z_{3}$. The local contact plane is configured by means of points $B^{\prime}, C^{\prime}$, and $D^{\prime}$. Hence, the contact point $H^{\prime}$ is determined as the geometrical center of triangle $\triangle B^{\prime} C^{\prime} D^{\prime}$. The height of point $H^{\prime}$ is described as:

$$
z_{H}^{\prime}=z 4+\left(\frac{z 2+z 3}{2}-z 4\right) \frac{1}{1+\tan (\gamma) / \tan (\omega)}
$$

- $\quad$ Point $B^{\prime}$ is without contact.

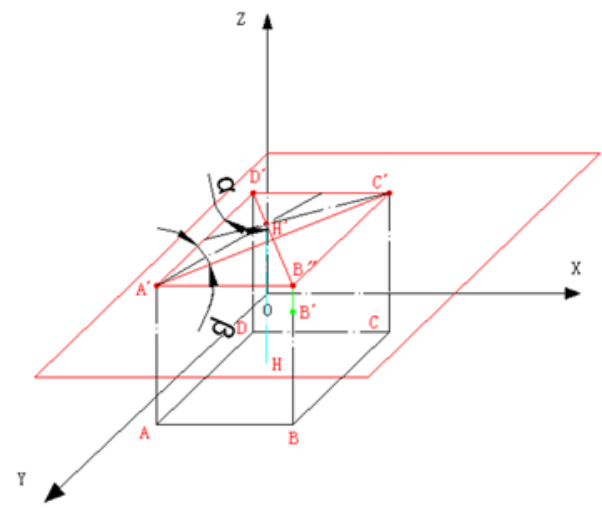

FIGURE VI. THE SPATIAL PRESENTATION OF LAUNCHING CONTACT POINT(B)

In this condition, as shown in Figure $\mathrm{V}$, point $B$ ' is without contact when $z_{2}<z_{1}+z_{3}-z_{4}$. The local contact plane is configured by means of points $A^{\prime}, C^{\prime}$, and $D^{\prime}$. Hence, the contact point $H^{\prime}$ is determined as the geometrical center of triangle $\triangle A^{\prime} C^{\prime} D^{\prime}$. The height of point $H^{\prime}$ is described as:

$$
z_{H}^{\prime}=z_{1}+\left(\frac{z_{2}+z_{4}}{2}-z_{1}\right) \frac{1}{1+\tan (\beta) / \tan (\alpha)}
$$

- $\quad$ Point $C^{\prime}$ is without contact.

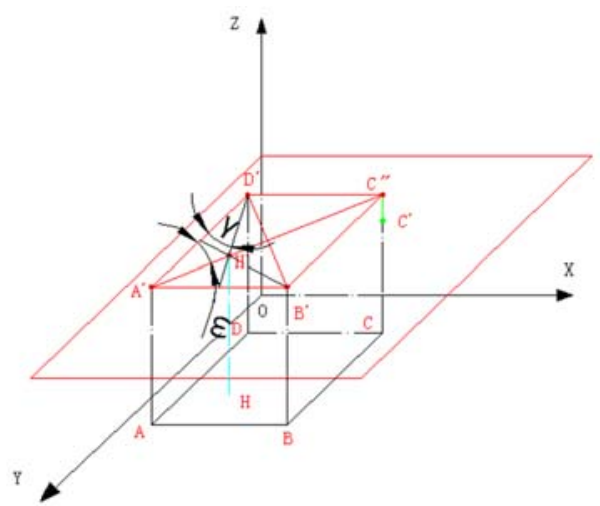

FIGURE VII. THE SPATIAL PRESENTATION OF LAUNCHING CONTACT POINT(C)

In this condition, as shown in Figure $\mathrm{V}$, point $C^{\text {' }}$ is without contact when $z_{3}<z_{2}+z_{4}-z_{1}$. The local contact plane is configured by means of points $A^{\prime}, B^{\prime}$, and $D^{\prime}$. Hence, the contact point $H^{\prime}$ is determined as the geometrical center of triangle $\triangle A^{\prime} B^{\prime} D^{\prime}$. The height of point $H^{\prime}$ is described as:

$$
z_{H}^{\prime}=z_{2}+\left(\frac{z_{1}+z_{4}}{2}-z_{2}\right) \frac{1}{1+\tan (\gamma) / \tan (\omega)}
$$

- $\quad$ Point $D^{\prime}$ is without contact.

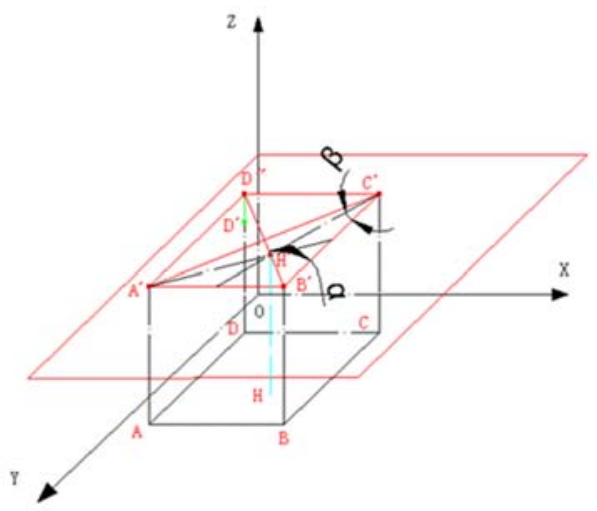

FIGURE VIII. THE SPATIAL PRESENTATION OF LAUNCHING CONTACT POINT(D)

In this condition, as shown in Figure $\mathrm{V}$, point $D^{\text {' is without }}$ contact when $z_{4}<z_{1}+z_{3}-z_{1}$. The local contact plane is configured by means of points $A^{\prime}, B^{\prime}$, and $C^{\prime}$. Hence, the contact point $H^{\prime}$ is determined as the geometrical center of triangle $\triangle A^{\prime} B^{\prime} C^{\prime}$. The height of point $H^{\prime}$ is described as: 


$$
z_{H}^{\prime}=z_{3}+\left(\frac{z_{1}+z_{2}}{2}-z_{3}\right) \frac{1}{1+\tan (\beta) / \tan (\alpha)}
$$

\section{B. Posture Detemination of Bridge Girder}

Once the posture of single IL device is available, the posture of the bridge girder can be determined by means of considering positions and orientations of multiple IL devices. The bridge girder is supposed to be a rigid body. Then, the launching movements of bridge girder can be described in Cartisian space in terms of three postures of known IL devices. The posture of the bridge girder is analyzed in three conditions.

- $\quad$ Lifting posture of the bridge girder.

As shown in Figure IX, the lifting heights of IL devices are $\mathrm{z}_{i j}$, where $i$ and $j$ are the index of a single IL device. By checking the lifting status of all available IL device whether they are fully contact with the bridge girder, the real contact points on the launching surface of the bridge girder can be determined.

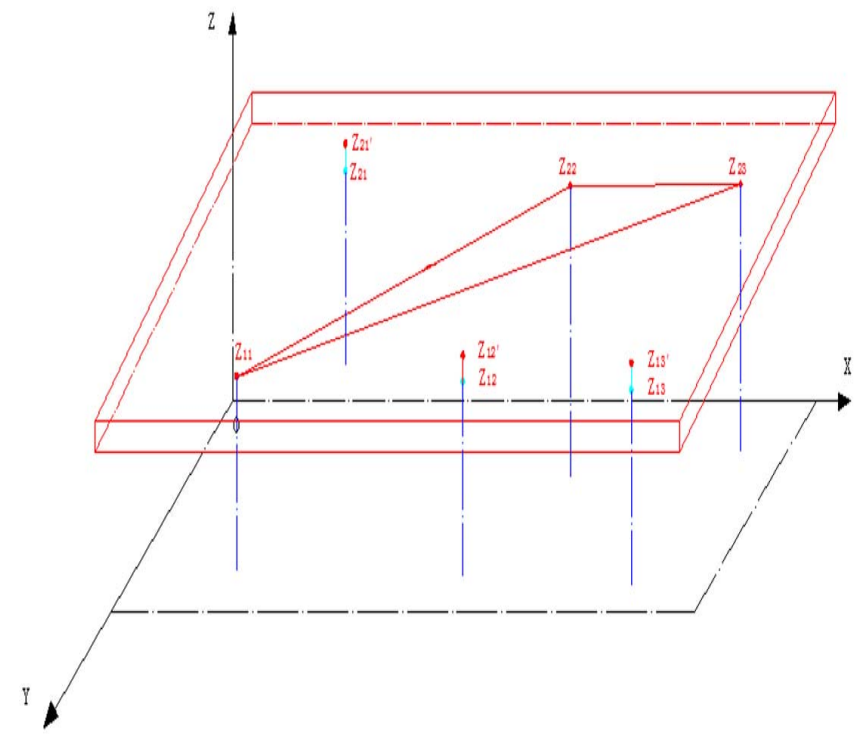

FIGURE IX. THE DESCRIPTION OF POSTURE FOR BRIDGE GIRDER LIFTING

For instance, the contact plane $\Xi_{M}$ is supposed to be constructed by points $z_{11}, z_{22}$ and $z_{23}$, then the distances between other IL devices and plane $\Xi_{M}$ are $z_{12} z_{12}, z_{13} Z_{13}$, and $z_{21} z_{21}$. If these distances, which can be obtained from corresponding position sensors in real-time, are equal or less than zero, the effective contact points are $z_{11}, z_{22}$ and $z_{23}$. Otherwise, $z_{12}, z_{13}$ and $z_{21}$ are not in contact status, until the following condition is satisfied.

$$
\Xi_{M}=\left\{z_{12} z_{12}^{\prime} \leq 0 \bigcap z_{13} z_{13}^{\prime} \leq 0 z_{21} z_{21}^{\prime} \leq 0\right\}
$$

- $\quad$ Pushing posture of the bridge girder.

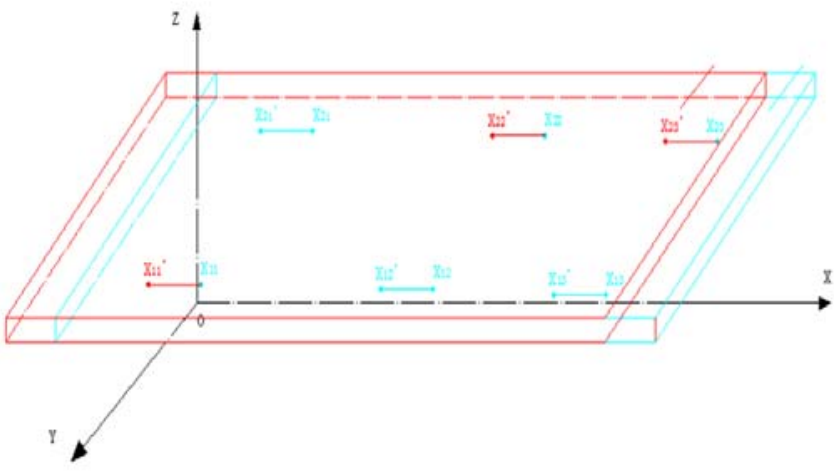

FIGURE X. THE DESCRIPTION OF POSTURE FOR BRIDGE GIRDER PUSHING

As shown in Figure $X$, the effective launching plane $\Xi_{M}$ is determined by point $z_{11}, z_{22}$ and $z_{23}$. The pushing distance of the bridge girder is therefore equal to the minimum value of $x_{11} x_{11}, x_{22} x_{22}$, and $x_{23} x_{23}$, which is due to the existence of sliding between the IL devices and bridge girder.

$$
x=\min \left\{x_{11} x_{11}^{\prime}, x_{22} x_{22}^{\prime}, x_{23} x_{23}^{\prime}\right\}
$$

- $\quad$ Adjusting posture of the bridge girder.

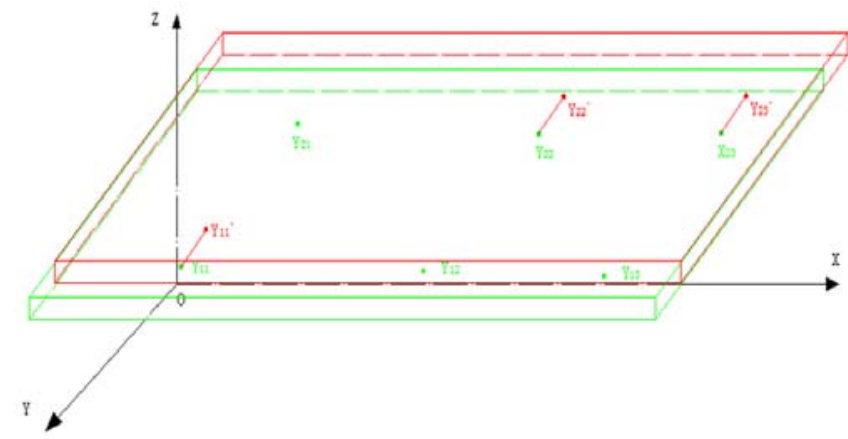

FIGURE XI. THE DESCRIPTION OF POSTURE FOR BRIDGE GIRDER ADJUSTING

As shown in Figure XI, the effective launching plane $\Xi_{M}$ is determined by point $z_{11}, z_{22}$ and $z_{23}$. The pushing distance of the bridge girder is therefore equal to the minimum value of $y_{11} y_{11}, y_{22} y_{22}$ ' and $y_{23} y_{23}$, which is due to the existence of sliding between the IL devices and bridge girder.

$$
y=\min \left\{y_{11} y_{11}^{\prime}, y_{22} y_{22}^{\prime}, y_{23} y_{23}^{\prime}\right\}
$$

In terms of analyzing the contact status of every single IL device and evaluating the real launching plane, the effective posture of the bridge girder is easily obtained.

\section{POSTURE SURVEILLANCE SYSTEM}

To realize the fine control of the bridge girder's posture during launching construction, hardware and software 
platform are established, in which the posture determination method is embedded.

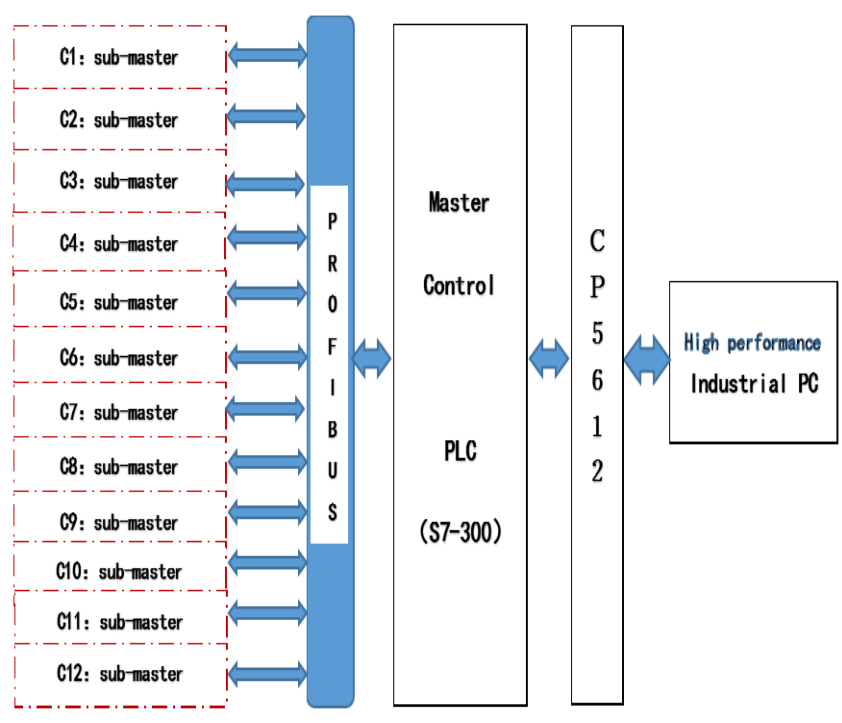

FIGURE XII. THE DESCRIPTION OF POSTURE FOR BRIDGE GIRDER PUSHING

To better monitoring the every local IL device's launching movements and its posture, a distributed PLC controlling system is configured. The number of the sub-master is corresponded with the construction requirement that every IL device is individually controlled by the local unit. The submaster controlling unit is responsible for the data monitoring and transferring. All the movements datum and hydraulics status are received by the remote master controlling unit, and then the digital launching commands are transferring back to the distributed sub-master controlling units. The master controlling unit is assembled with a high performance industrial PC to compute the launching status and evaluate whether the current posture of the bridge girder is within the launching trajectory tolerance. For more, the HMI surveillance interface is design to monitor the posture of the bridge girder, which is shown in Figure. XIII.

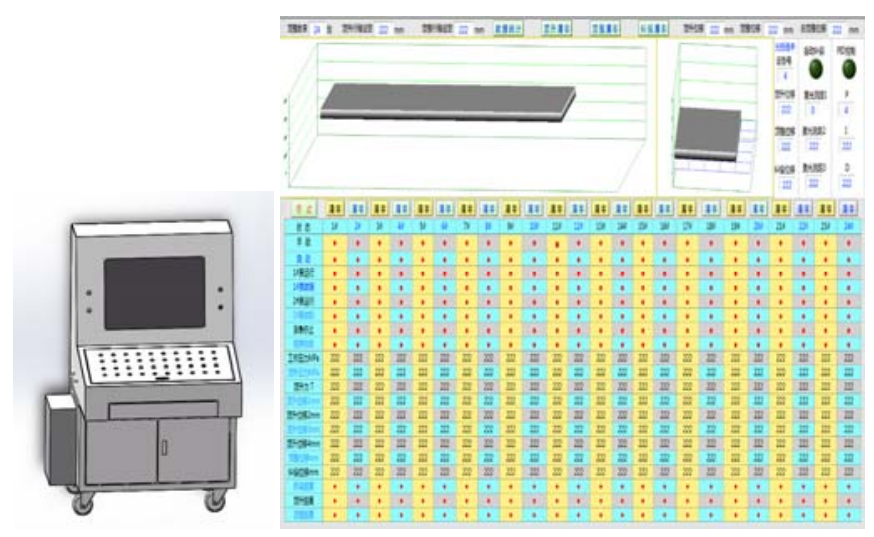

FIGURE XIII. THE HMI SURVEILLANCE PLATFORM
V. ApPliCATION OF LAUNCHING CONSTRUCTION IN PRACTICE
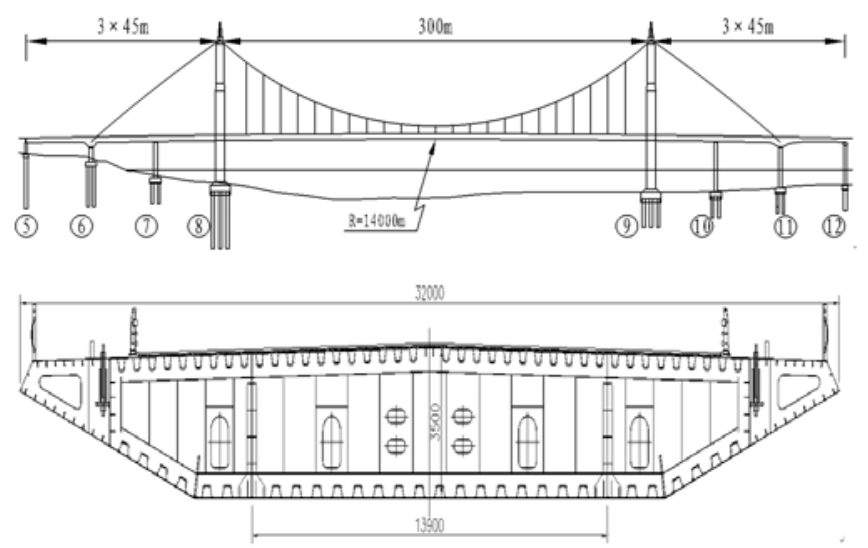

FIGURE XIV. ZHUZHOU FENGXI SUSPENSION BRIDGE GENERAL CONSTRUCTION LAYOUT

Fengxi suspension bridge is a typical self-anchored suspension bridge in Zhuzhou City, China. The main span of the bridge is made of steel box girder, the structure feature of which is shown in Figure XIV. The working interface of the steel box girder is $13.9 \mathrm{~m}$ wide flat-type plane. Total weight of the bridge girder is up to 529 tonne.

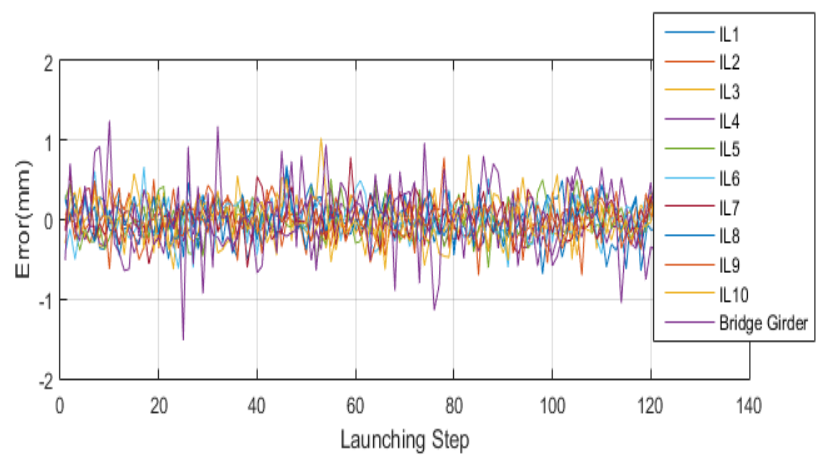

FIGURE XV. LAUNCHING TRAJECTORY ERRORS(MM)

There are $10 \mathrm{IL}$ devices used to launch the main span of bridge girder. Considering the complex construction condition and the large span-weight ratio, the fine control of posture of the pre-fabricated steel box girder during launching plays a vital role to the safety and efficiency of the construction.

In terms of applying the posture determination method and the surveillance system, the posture of the bridge girder and each IL device are well controlled that launching trajectory errors is less than 3mm, which is shown in Figure XV.

\section{CONCLUSION}

This paper proposed a mathematical method for determining the position and orientation of bridge girder and distributed Incremental Launching devices. The launching movements and the hydraulic system are introduced in brief. The mathematical description of the posture for single device and the bridge girder are drawn and analyzed. The posture 
determination method is assemble into the bridge launching construction surveillance system and the effectiveness of this method is verified in terms of the practical application in the launching construction of Fengxi suspension bridge.

\section{ACKNOWLEDGMENT}

This work is supported by research and development projects of CCCC Second Harbor Engineering Company Ltd., which are "Special equipment Intelligent Monitoring System" and "The Visual Pose Control System of Incremental Launching Devices". Also, the authors would like to thank the Fourth Subsidiary of CCCC Second Harbor Engineering Company Ltd., and its engineers for their kind help and advice on launching construction.

\section{REFERENCES}

[1] R. Marco, “Bridge Launching,” Thomas Telford, London, 2002

[2] M. Rosignoli, "Self-launching erection machines for precast concrete bridges,” J. PCI. Vol. 55(1), pp. 36-57, 2010

[3] W. Zellner, H. Svensson, "Incremental Launching of structures,” ASCE. J. Struct. Eng. Vol. 0733-9445. 109:2, pp. 520-537, 1983

[4] J.F. Wang, J.P. Lin, R.Q. Xu, "Incremental launching construction control of long multispan composite bridges,” ASCE. J. Bridge Eng. Vol. 1084-0702. 04015006, pp. 1-9, 2015

[5] Y.M. Bian, J. Jiang, B.X. Han, A.H. Li, G.J. Liu, "Design and Application of Hydraulic-Walking incremental Launching equipment,” J. the open Constr. Build. Technol. Vol. 7(1), pp. 1-7, 2013

[6] B. Kisch, P. Langefors, "Incremental launching versus Scaffolding for construction of Prestressed concrete bridges,” Mast. Thesis. Chalmers Univ. of Technol, 2005

[7] K. Jung, K. Kim, C. Sim, J. Kim, "Verification of incremental launching construction safety for the ilsun bridge, the world's longest and widest prestressed concrete box girder with corrugated steel web section,” J. Bridge. Eng. Vol. 16(3), pp. 453-460, 2011

[8] Z. H. Zhang, J. Y. Zhang, W. S. Hao, J. G. Dai and Y. Shen, "Hangzhou Jiangdong Bridge designed as a spatial self-anchored suspension bridge,” J. Struct. Eng. Int. vol. 20(3), pp. 303-307, 2010

[9] C.Y. Shao, "Key technological study of long span continuous composite box girder bridges,” PhD. Thesis. Tongji Univ, 2007

[10] A. N. Fontan, J. M. Diaz, A. Baldomir and S. Hernandez, "Improved optimization formulations for launching nose of incrementally launched prestressed concrete bridges,” ASCE. J. Bridge Eng. Vol. 1943-5592. 000016916, pp. 461-470, 2011

[11] F.G. Michele, "Analysis of non-uniform torsion in curved incrementally launched bridges,” J. Eng. Str. Vol. 75, pp. 374-387, 2014 